\title{
O chat como ambiente de produção de significados para tarefas de Educação Financeira
}

\author{
Meiriele Nonato de Oliveira Saiol \\ Escola Estadual Duque de Caxias \\ Secretaria Estadual de Educação/MG \\ meirinonato@yahoo.com.br

\section{Leonardo José da Silva} \\ Colégio de Aplicação João XXIII \\ Universidade Federal de Juiz de Fora, Brasil \\ leonardo.silva@ufjf.edu.br
}

\section{Resumo \\ O presente artigo apresenta uma investigação das interações e produção de significados de estudantes a partir de tarefas sobre Educação Financeira discutidas em um chat. A pesquisa, de cunho qualitativo, foi desenvolvida com estudantes do $9^{\circ}$ ano do ensino fundamental de uma escola pública. A produção de significados e as interações ocorridas entre os estudantes foram analisadas com o apoio de uma ferramenta analítica de categorização das falas e fundamentada pelo Modelo dos Campos Semânticos.}

Palavras-chave: Educação Matemática. Chat. Educação Financeira. Modelo dos Campos Semânticos. Produção de significados.

\section{Chat as na environment of meaning production for financial educations tasks}

\begin{abstract}
The present article presents an investigation of the interactions and production of meanings of students from the tasks on Financial Education discussed in a chat. The qualitative research was developed with students of the 9th grade of a public school. The production of meanings and the interactions that took place among the students were analyzed with the support of an analytical tool for categorizing speeches and based on the Semantic Fields Model.
\end{abstract}

Keywords: Mathematic Education. Chat. Financial Education. Semantic Fields Model. Production of Meaning. 


\section{Introdução}

Este artigo é parte de uma pesquisa intitulada Chat e Educação Financeira Escolar: investigando interações em um ambiente virtual de aprendizagem ${ }^{1}$. O objetivo da investigação foi produzir tarefas sobre Educação Financeira para serem discutidas nas aulas de matemática por estudantes do $9^{\circ}$ ano do ensino fundamental por meio de chats da Internet, bem como analisar as interações de mensagens curtas ocorridas entre estudantes e professor, durante a produção de significados dos participantes para as tarefas propostas.

A preocupação com os estudantes diante do quadro da sociedade contemporânea na qual vivemos foi um ponto motivacional de nossa pesquisa. De um lado, estamos inseridos em uma sociedade líquido-moderna em constante transformação, inóspita ao planejamento, como observou Bauman (2008). De outro lado, vivemos em uma sociedade mergulhada em tecnologia, presente na comunicação entre as pessoas, no modo de comprar, nas transações bancárias, mas infelizmente em uma escala bem menor de utilização no campo educacional.

Além disso, um outro ponto que instigou nossa investigação foi o interesse em entender a produção de significados dos estudantes para tarefas envolvendo temas de Educação Financeira em ambientes virtuais. Para isso, necessitamos quebrar com o tradicionalismo das aulas de matemáticas voltadas para a fala do professor, tido como detentor e transmissor do conhecimento, dificultando, dessa forma, o diálogo em sala de aula e muitas vezes impedindo a leitura da produção de significado dos alunos.

Assim, o presente artigo se apropria do Modelo dos Campos Semânticos (MCS) e apresenta o modo como aconteceu a investigação das interações e produção de significados dos alunos por meio do chat.

\section{Educação Financeira nas escolas}

A Educação Financeira tem sido um tema que vem ganhando espaço na pesquisa em Educação Matemática e sua inserção no ambiente escolar vem sendo defendida por professores e pesquisadores. De fato, essa questão tem ganhado destaque a partir da proposta da Organização para Cooperação e Desenvolvimento Econômico (OCDE) que em 2003 lançou o Programa de Educação Financeira nas escolas. No entanto, um de seus países membros, os Estados Unidos, já tem relatos de trabalho com o tema nas escolas que datam da década de 80, no século XX (SILVA; POWELL, 2013, 2014).

\footnotetext{
${ }^{1}$ Dissertação de Mestrado em Educação Matemática/UFJF.
} 
A relevância da Educação Financeira nas escolas é argumentada pela OCDE em seu relatório de 2008 em que revela que os gastos das crianças têm impactado a despesa das famílias; os jovens estão se arriscando cada vez mais ao adquirir dívidas altas que podem comprometer o seu futuro financeiro e muitos pais não têm condição de instruir os filhos financeiramente, quando não gerenciam bem o próprio dinheiro, por falta de conhecimento. Esses são alguns argumentos usados pela organização para sugerir o ensino do tema na escola (SILVA; POWELL, 2014).

Além dos pontos que evidenciam a importância da educação financeira para a vida dos cidadãos, o relatório da OCDE destaca a melhor fase escolar para iniciar o assunto. Segundo Mundy (2008), o tema deve ser introduzido no início da vida escolar, já que as crianças estão com a mente aberta para receberem novos conceitos. Toda a proposta da OCDE tem seu foco na formação dos indivíduos de forma a saberem administrar bem as finanças pessoais ( SILVA; POWELL, 2014).

O Brasil não é um país membro da OCDE, mas mantém laços com ela. As propostas de educação financeira brasileira existentes têm influências claras do programa da Organização. No ano de 2007 iniciou uma proposta de grupo de estudo para implantação da Educação Financeira em âmbito nacional. Três anos depois, em 2010, foi criada a Estratégia Nacional de Educação Financeira (ENEF) que busca ações que contribuam com a tomada de decisão mais consciente dos indivíduos. Assim como a OCDE, a ENEF objetiva implantar a Educação Financeira nas escolas públicas.

O Programa Educação Financeira nas Escolas, naquele período, sob a coordenação do Instituto Unibanco, criou e disponibilizou materiais didáticos inicialmente para o Ensino Médio e, a partir de 2016, para todos os anos do Ensino Fundamental. O material é composto por Livro do Professor, Livro e Caderno do Aluno. Todo material é encontrado de forma gratuita na Plataforma Aberta $^{2}$, lançada em 2014.

A ENEF adota como referência o conceito de Educação Financeira criado pela OCDE, definindo-a como sendo

o processo mediante o qual os indivíduos e as sociedades melhoram sua compreensão em relação aos conceitos e produtos financeiros, de maneira que, com informação, formação e orientação, possam desenvolver os valores e as competências necessários para se tornarem mais conscientes das oportunidades e dos riscos nele envolvidos e, então, poderem fazer escolhas bem informadas, saber onde procurar ajuda, adotar outras ações que melhorem o seu bem-estar. Assim, podem contribuir de modo mais consciente para a formação de indivíduos e sociedades responsáveis, comprometidos com o futuro. (BRASIL, 2018,p.)

\footnotetext{
2 Todo material didático do "Programa Educação Financeira nas Escolas" é encontrado no site: http://www.vidaedinheiro.gov.br/
} 
Compreendemos Educação Financeira no âmbito escolar e social de forma mais abrangente. A Educação Financeira considerada em nosso trabalho constitui-se em

um conhecimento que pode orientar os estudantes a tomarem decisões críticas e conscientes diante de diversas situações do cotidiano no universo financeiroeconômico, integrando conteúdos básicos da Matemática e da Matemática Financeira, bem como conceitos matemáticos a contextos socioculturais envolvendo ética e sustentabilidade na gestão do dinheiro, com a utilização de múltiplos recursos, como o uso das tecnologias digitais e a utilização de materiais alternativos, manipuláveis. (SAIOL, 2017, p.)

Com essa visão de Educação Financeira, desenvolvemos a pesquisa. As tarefas foram elaboradas com o objetivo de orientar os alunos na tomada de decisões financeiras críticas e conscientes diante de situações cotidianas, sempre integrando conteúdos matemáticos com contextos socioculturais e a utilização da tecnologia. Em particular, a tarefa apresentada aqui tem o contexto social do desemprego. A tecnologia durante todo o trabalho está presente na utilização do chat como ferramenta educacional.

\section{O chat como ferramenta educacional}

O chat é um termo em inglês traduzido como bate-papo, conversa. É uma ferramenta síncrona que permite a participação de duas ou mais pessoas, muito utilizada para interações informais, repleta de gírias, abreviações e pouca preocupação ortográfica (SILVA, 2013). Por exigir uma conexão simultânea de seus participantes, o chat é marcado por uma grande fluidez de texto, sendo necessária por vezes a utilização de símbolos que exprimam expressões faciais, os emoticons.

No campo educacional, contamos com contribuições didático-pedagógicas vindas da pesquisa. Bairral (2007), por exemplo, revela que esse tipo de interação - a síncrona, é a preferida dos estudantes principalmente quando se faz uso de vídeos e similares. Quanto à quantidade de integrantes na formação de grupos para as interações, Horton (2000) destaca que deva ser um número entre 5 e 7 participantes, já que valores inferiores a esses podem gerar cansaço. $\mathrm{O}$ outro extremo também pode ser comprometedor; Bairral (2004) entende que chat com número elevado de participantes pode prejudicar o acompanhamento das discussões.

Com base nessas informações, nosso trabalho envolveu a participação de alunos no chat organizados em dois grupos de sete integrantes com o objetivo de analisar as interações e produção de significados dos sujeitos de pesquisa para as tarefas de educação financeira.

\section{Pressupostos teóricos: O Modelo dos Campos Semânticos}

Todo trabalho desenvolvido durante a pesquisa buscando investigar a prática discursiva dos alunos e do professor é pautado no Modelo dos Campos Semânticos (MCS). Tarefas foram elaboradas para 
estimularem interações entre os sujeitos de pesquisa e a produção de significado destes para temas financeiro-econômicos. As análises das interações e da produção de significado dos estudantes foram feitas por meio de categorizações das mensagens do bate-papo de acordo com padrões comunicativos identificados. Tais categorias foram minuciosamente pensadas levando em consideração o MCS, como o leitor poderá observar adiante.

O modelo epistemológico do educador matemático Romulo Campos Lins parte de alguns pressupostos que orientaram nossa investigação, por exemplo, a concepção de conhecimento, significado e comunicação. Para ele, somos naturalmente diferentes em nosso desenvolvimento cognitivo e dar voz aos alunos e ler suas falas e registros escritos são de fundamental importância nos processos de ensino e aprendizagem. Nessa direção, Lins afirma:

Não sei como você é, preciso saber. Não sei também onde você está (sei apenas que está em algum lugar); preciso saber onde você está para que eu possa ir até lá falar com você e para que possamos nos entender, e negociar um projeto no qual eu gostaria que estivesse presente a perspectiva de você ir a lugares novos. (LINS, 1999, p. 85)

Seguindo essa linha, definimos como pontos centrais de nossa fundamentação teórica as noções de conhecimento, significado, objeto e processo comunicativo.

Segundo Lins (1999, p.88), conhecimento é “uma crença-afirmação com uma justificação que me autoriza a produzir aquela enunciação".

Portanto para que o conhecimento seja produzido, não basta acreditar e enunciar, é necessário que o sujeito faça a justificação, conforme explicitado por Silva:

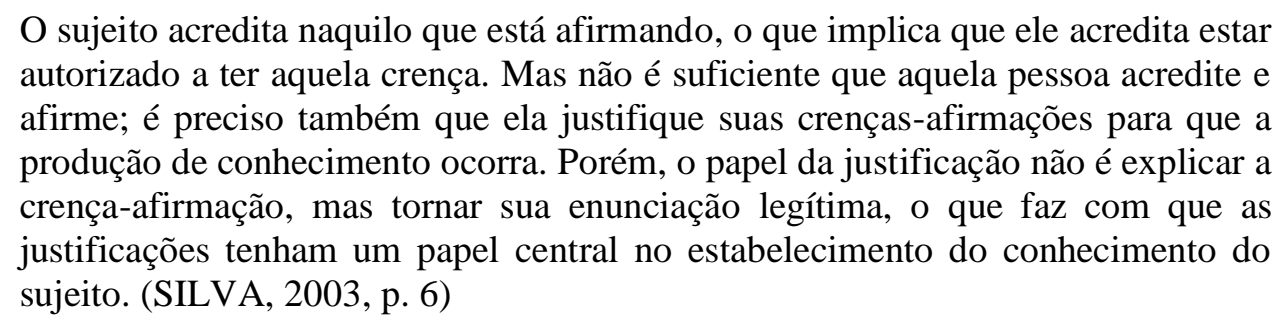

Outra noção central do MCS é a de significado. O significado de um objeto deve ser entendido como sendo "aquilo que efetivamente se diz a respeito de um objeto no interior de uma atividade" 3", assim, “objeto é aquilo para que se produz significado" (LINS, 2012, p.). Portanto, produzir significado é "produzir ações enunciativas a respeito de um objeto no interior de uma atividade" (SILVA, 2003, p.9).

O processo comunicativo é formado pelos elementos autor, texto e leitor. O sujeito que produz enunciação é considerado o autor, podendo ser um professor durante uma aula expositiva ou

\footnotetext{
${ }^{3}$ No sentido proposto por Leontiev. (LEONTIEV, sd)
} 
um artista apresentando sua obra, conforme sugere Silva (2003). O leitor corresponde àquele que se propõe a produzir significados diante do que está sendo enunciado, como, por exemplo, um aluno tentando entender a explicação do professor ou um crítico de arte observando obras em uma exposição. E por último, mas não menos importante, o texto entendido como qualquer resíduo de enunciação para o qual o leitor produza significado.

É interessante destacar que na análise do processo comunicativo, o autor sempre fala para um leitor; mesmo que esse autor esteja diante de uma plateia, ele não fala a indivíduos e sim a um leitor. (LINS, 1999) Além disso, ao se fazer a leitura do texto enunciado é necessário olhar com os olhos do autor a fim de se fazer uma leitura plausível. Lins afirma que

[...] toda tentativa de se entender um autor deve passar pelo esforço de olhar o mundo com os olhos do autor, de usar os termos que ele usa de forma que torne o todo de seu texto plausível e é aqui que devemos prestar atenção às definições que um autor propõe. (LINS, 1999, p.93)

O processo comunicativo e os demais elementos do MCS apresentados estão inseridos em toda metodologia de nossa pesquisa. As tarefas de educação financeira foram elaboradas de forma a serem disparadoras da produção de significados dos estudantes para temas financeiro e econômicos. A ferramenta analítica de categorização das mensagens criada leva em consideração a essência dos termos autor, texto e leitor. E os pesquisadores trabalham com a leitura plausível das mensagens, dando voz aos alunos e se prendendo a entender a produção de significados dos estudantes a partir dos resíduos de enunciações de suas ações enunciativas.

\section{Caracterização da pesquisa}

A pesquisa de cunho qualitativo e participante foi realizada por meio do chat com alunos de uma turma que iniciava o $9^{\circ}$ ano do ensino fundamental em uma escola pública da região central de Juiz de Fora, Minas Gerais. A turma foi selecionada após um levantamento feito pela professorapesquisadora do número de estudantes que possuía acesso à Internet por computador e/ou smartphone. A sondagem revelou que todos os 33 alunos tinham acesso à Internet. A relação entre o tipo de aparelho usado para essa conexão e o número de alunos pode ser visto no quadro a seguir.

Quadro 1:Aparelho de acesso à Internet

\begin{tabular}{|l|c|}
\hline \multicolumn{2}{|c|}{ ALUNOS QUE UTILIZAM INTERNET } \\
\hline No computador de casa & 27 \\
\hline Apenas no cellular & 6 \\
\hline
\end{tabular}




\section{Fonte: Dados da pesquisa}

Apenas o acesso à Internet não era suficiente para iniciar o projeto, mas os estudantes também precisavam se dispor a participar. Em um primeiro momento, a tarefa a ser realizada no bate-papo valeria nota de matemática para o bimestre. No entanto, nem todos os alunos acessaram o chat como o combinado. Por isso, após os interessados se familiarizarem com o aplicativo, utilizamos de um segundo instante para fazer a pesquisa com os adolescentes que se dispuseram a participar. Dois grupos de sete alunos participantes foram formados para a pesquisa, dos quais a professora-pesquisadora também fazia parte como mediadora das interações.

Quatro tarefas de educação financeira fundamentadas com as concepções do MCS foram criadas para serem discutidas por esses grupos no chat. Na pesquisa foi utilizada apenas a primeira. A totalidade das tarefas deu origem à parte de um produto educacional ${ }^{4}$ destinado a professores de Matemática que desejam trabalhar educação financeira com alunos de $9^{\circ}$ anos do ensino fundamental. O outro conteúdo do produto educacional é um tutorial para se trabalhar as tarefas com chat.

O bate-papo selecionado para o trabalho foi o Hangouts, um aplicativo do Google, de tecnologia acessível e de fácil utilização, que exige apenas uma conta Google, um computador ou smartphone e Internet para utilização. As interações ocorreram em duas aulas chats efetivas, isto é, em duas seções de bate-papo realizadas em dias distintos, com duração média de duas horas cada aula.

Para a análise das interações e produção de significados dos estudantes foi criada uma ferramenta de categorização das mensagens trocadas por meio do chat, baseada em Silva (2013) e Flanders $^{5}$ (1970, apud GONZÁLES and LEÓN, 2009) e com foco no MCS. Assim, categorias elaboradas se direcionavam para as afirmações e justificações dos sujeitos.

\section{A ferramenta analítica}

Focando os pontos anteriormente mencionados, organizamos as mensagens das aulas chats. Inicialmente os textos foram anexados a uma tabela criada com identificação do número de data da aula e composta por cinco colunas, conforme o Quadro 1, a saber: número da mensagem, horário, identificação de quem a enviou (Autor), identificação para quem está sendo direcionada (Leitor), texto escrito pelo Autor (Mensagem) e Categoria.

\footnotetext{
${ }^{4} \mathrm{O}$ produto educacional completo pode ser acessado em: http://www.ufjf.br/mestradoedumat/publicacoes/produtoseducacionais/

${ }^{5}$ Colocar aqui a referência primária
} 
Quadro 1 - Cabeçalho da tabela em que foram organizadas as mensagens dos chats

\begin{tabular}{|c|c|c|c|c|c|}
\hline \multicolumn{7}{|c|}{$X^{\text {a }}$ AULA CHAT - XX DE MAIO } \\
\hline $\mathbf{N}^{\mathbf{0}}$ & Hora & Autor & Leitor & Mensagem & Categoria \\
\hline
\end{tabular}

Fonte: Elaborado pelos autores

A coluna "Categoria" foi designada para mensagens escritas pelos alunos conforme o conteúdo sob o olhar da professora-pesquisadora. As categorias foram criadas posteriormente às interações, de acordo com um padrão comunicativo, e totalizam o número de seis. Foram identificadas mensagens nas quais os alunos respondiam tanto questões da Tarefa quanto alguma pergunta de outro integrante do grupo; faziam perguntas a membros participantes; usavam algum recurso computacional; criticavam a postura ou fala de um colega; mostravam afeto, humor ou brincadeira a algum membro do grupo; ou simplesmente cumprimentavam-se ou despediam-se uns dos outros.

Baseado em Silva (2013), cada categoria recebeu um código analítico para facilitar o trabalho, conforme pode ser verificado na tabela $1^{6}$. Dentre as seis categorias, "Aluno Perguntando" e "Aluno Respondendo" foram subdivididas, servindo de auxílio para melhor compreensão das trocas de mensagens curtas por estudantes em uma aula chat e também para análise das produções de significados dos sujeitos de pesquisa. No total das divisões, oito subcategorias foram obtidas, sendo duas para "Aluno Perguntando" e seis para "Aluno Respondendo".

Um ramo destacado da categoria "Aluno Respondendo" é a subcategoria "Justifica sua crença-afirmação" (ARJ). Através do número de ocorrências dela foi possível detectar a dimensão da produção de conhecimento dos sujeitos de pesquisa durante a participação nas aulas chats.

Para melhor compreensão do leitor, a tabela para categorização das mensagens dos alunos pode ser acompanhada a seguir.

Tabela 2: Categorias da participação dos alunos

\begin{tabular}{|c|l|c|c|}
\hline \multicolumn{4}{|c|}{ PARTICIPAÇÃO DOS ALUNOS } \\
\hline Categoria & \multicolumn{1}{|c|}{ Subcategoria } & Código & Ocorrências \\
\hline \multirow{2}{*}{ Perguntando } & $\begin{array}{l}\text { Pergunta direcionada a } \\
\text { Professora }\end{array}$ & APP & \\
\cline { 2 - 4 } & $\begin{array}{l}\text { Pergunta } \\
\text { direcionada aos Colegas }\end{array}$ & APC & \\
\hline \multirow{2}{*}{ Respondendo } & $\begin{array}{l}\text { Responde sem } \\
\text { Justificar }\end{array}$ & AR & \\
\cline { 2 - 4 } & $\begin{array}{l}\text { Responde } \\
\text { Concordando }\end{array}$ & ARC & \\
\hline
\end{tabular}

\footnotetext{
${ }^{6}$ Não serão detalhadas aqui todas elas, apenas as mais significativas para o estudo em questão.
} 


\begin{tabular}{|c|c|c|}
\hline & $\begin{array}{l}\text { Responde } \\
\text { Discordando }\end{array}$ & ARD \\
\hline & $\begin{array}{l}\text { Posiciona sobre } \\
\text { seu entendimento }\end{array}$ & ARP \\
\hline & $\begin{array}{l}\text { Exemplifica afirmação } \\
\text { sua ou } \\
\text { de um colega }\end{array}$ & ARE \\
\hline & $\begin{array}{l}\text { Justifica sua } \\
\text { crença-afirmação }\end{array}$ & ARJ \\
\hline $\begin{array}{c}\text { Utilizando Recursos } \\
\text { Computacionais }\end{array}$ & $\begin{array}{l}\text { O aluno utiliza } \\
\text { internet para obter } \\
\text { informações } \\
\text { relevantes quanto à } \\
\text { resolução da } \\
\text { Tarefa }\end{array}$ & AURC \\
\hline $\begin{array}{l}\text { Aceitando } \\
\text { Sentimentos }\end{array}$ & $\begin{array}{l}\text { Presença de aluno, } \\
\text { Humor, Brincadeiras } \\
\text { entre si, Carinho com } \\
\text { o colega, e Aluno } \\
\text { externando questões } \\
\text { pessoais. }\end{array}$ & AAS \\
\hline Crítica & $\begin{array}{l}\text { Aluno não concorda } \\
\text { com o comportamento } \\
\text { do colega ou faz } \\
\text { ironias em relação } \\
\text { ao colega. }\end{array}$ & $\mathrm{AC}$ \\
\hline Outros & $\begin{array}{l}\text { Aluno chega e sai do } \\
\text { chat, se } \\
\text { organizam, tenta } \\
\text { trocar seu perfil por } \\
\text { pseudônimo, } \\
\text { cumprimenta ou se } \\
\text { despede de colegas, } \\
\text { além de enunciados } \\
\text { incompreensíveis. }\end{array}$ & Outro \\
\hline
\end{tabular}

Fonte: Elaborado pelos autores

\section{A tarefa investigativa}

A tarefa investigativa utilizada durante a pesquisa refere-se à primeira dentre as quatro tarefas elaboradas para compor o produto educacional. Ela é iniciada com um texto que possui papel fundamental de disparador de interações e produção de significados. Esse texto traz a história de uma família que utilizava o cartão de crédito constantemente sem planejamentos e se deparou com o desemprego do sr. João, provedor financeiro do lar. 


\section{O drama das famílias frente à crise financeira vivenciada no Brasil}

Juiz de fora é uma cidade da Zona da Mata, Minas Gerais, com mais de 500 mil habitantes, de acordo o Instituto Brasileiro de Geografia e Estatística (IBGE). No ano de 2016, mediante a crise econômica que afetou o Brasil, a cidade teve 49.282 demissões, frente a 46.913 contratações com carteira assinada. Os dados são do Cadastro Geral de Empregados e Desempregados (Caged) e foram divulgados em dezembro desse ano.

Nascido e criado em Juiz de Fora, Sr. João (42) é casado com Dona Janaína (39) e pai de Ana Júlia (14). O vendedor, que sempre trabalhou em lojas de eletrodoméstico, sentiu o peso da crise no segundo semestre de 2016.

Segundo ele, sua renda em 2015 era, em média, R\$ 2600,00, já que recebia salário mais comissão. Atualmente desempregado, recebe apenas o salário mínimo da classe como seguro desemprego, $\mathrm{R} \$ 1056,00$. "Nunca fui de colocar no papel meus ganhos e gastos, mas agora, tentando não deixar faltar o básico em casa, estou tendo que aprender a fazer o orçamento familiar", afirmou.

Já Dona Janaína, que não trabalhava fora anteriormente, conseguiu um emprego na loja de artigos para festas na contratação temporária de fim de ano e foi efetivada na loja no mês passado, ganhando um salário mínimo. Conversando com ela, dona Janaína confessou: "Mesmo eu trabalhando agora, estamos tendo que apertar o cinto e fazer vários cortes nos gastos. Passeios e lanches fora de casa, nem pensar! Vamos pagar o mínimo da fatura do cartão, que é o que permite nosso ganho atual. Pois mesmo tentando não utilizar mais o cartão de crédito já fizemos várias compras no mês passado que vieram nesse mês."

A história de Sr. João e Dona Janaína resume não só a situação de várias famílias da cidade mineira como também revela as dificuldades das famílias brasileiras diante da crise econômica atual do nosso país.

E para saírem das dívidas, os economistas dizem que é preciso muita disciplina e comprometimento. Cartão de crédito, só em casos de emergências!

A partir da leitura do texto os estudantes foram convidados a ajudar a família do Sr. João por meio da reflexão e discussão de algumas questões. Cinco questões foram apresentadas, uma por vez. À medida que os alunos discutiam uma questão, outra era inserida no chat. 
Diante do drama vivenciado pela família do Sr. João, vamos analisar o orçamento feito por ele no último mês e entender um pouco melhor sua situação financeira:

\begin{tabular}{lc}
\hline \multicolumn{1}{c}{ DESCRITIVO DAS DESPESAS } & VALOR R\$ \\
\hline Financiamento da casa própria & $\mathrm{R} \$ 530,00$ \\
$\begin{array}{l}\text { Contas (água, luz, telefone, } \\
\text { internet, TV) }\end{array}$ & $\mathrm{R} \$ 242,00$ \\
\hline $\begin{array}{l}\text { Alimentação (supermercado, feira, } \\
\text { açougue, padaria, lanches) }\end{array}$ & $\mathrm{R} \$ 550,00$ \\
$\begin{array}{l}\text { Transporte (ônibus, combustível) } \\
\text { Cartão de crédito (roupas, passeios, } \\
\text { aparelho celular) }\end{array}$ & $\mathrm{R} \$ 200,00$ \\
\hline $\begin{array}{l}\text { Saúde (remédios, plano de saúde) } \\
\text { DESPESA TOTAL }\end{array}$ & $\mathrm{R} \$ 1000,00$ \\
\hline
\end{tabular}

Sr. João e Dona Janaína já fizeram as contas e sabem que mesmo juntando o dinheiro dos dois, não conseguirão quitar todas as contas. Diante disso, resolveram pagar o valor mínimo da fatura do cartão de crédito, já que assim o restante das contas ficará em dia.

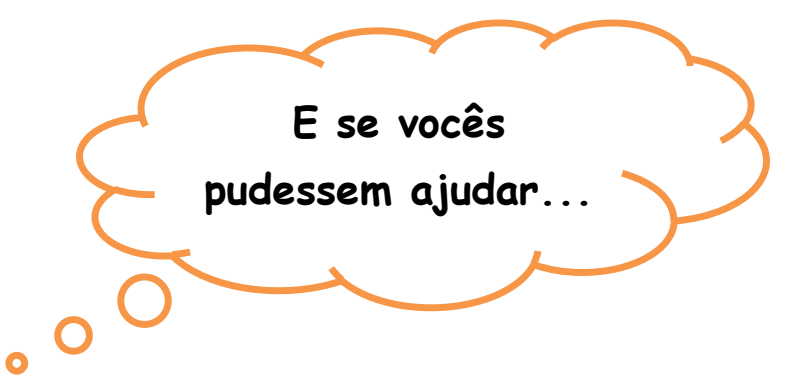

Vamos tentar ajudar essa família a resolver o problema financeiro da melhor forma possível! Para isso pensaremos em algumas coisas:

$\left.\mathbf{1}^{\mathbf{0}}\right)$ Vocês concordam que a fatura do cartão de crédito deva ser deixada em últimos planos no pagamento das contas? Por quê?

$\left.\mathbf{2}^{\circ}\right)$ Será que Sr. João optou pela melhor forma de pagamento da fatura do cartão de crédito? Para fazerem essa verificação, acompanhem as opções de pagamento da fatura e as questões que se seguem: 
Analisem as opções de pagamento e respondam:

a) Qual valor deverá ser pago para pagamento mínimo? Sr. João tem condições de pagar esse valor em maio?

b) Qual a taxa de juros utilizada para o pagamento mínimo do valor de uma fatura?

c) Qual a média da taxa de financiamento/parcelamento de uma fatura? Sr. João pode pagar o parcelamento sugerido na fatura?

d) Vocês sabem a média dos juros cobrados pelos bancos para utilização do cheque especial? Caso não saibam, pesquisem e calculem a média.

e) Vocês sabem a média dos juros cobrados pelos bancos (financeiras) para empréstimo pessoal de dinheiro? Caso não saibam façam uma pesquisa em pelo menos três bancos distintos e calcule essa média.

f) A partir dos dados coletados acima, completem a tabela a seguir:

Média Da Taxa De Juros Do Cartão De Crédito em \% ao mês (Ano 2017)

Pagamento mínimo

Financiamento/parcelamento

Empréstimo pessoal

\section{Cheque especial}

$3^{\text {o }}$ ) Agora que vocês já sabem a média de todas as taxas de juros cobradas pelos bancos em vários casos distintos, analisem a fatura do Sr. João, façam os cálculos necessários e marquem a opção em que irão pagar menos juros possíveis. 


\begin{tabular}{l}
\hline a) Utilizando $\mathrm{R} \$ 150,00$ do salário para pagar o mínimo. \\
b) Dividir o valor da fatura em $24 x$. \\
c) Fazer um empréstimo de $\mathrm{R} \$ 1000,00$. \\
d) Utilizar $\mathrm{R} \$ 1000,00$ do cheque especial para pagar a fatura. \\
$\mathbf{4}^{\mathbf{0}}$ ) Sr. João conseguiu um emprego e sua carteira de trabalho foi \\
assinada com um salário mínimo após os cinco meses que ele ficou \\
recebendo o seguro desemprego. Agora ele pensa se todo esse \\
tumulto financeiro poderia ter sido evitado, mesmo que ele fosse \\
atingido pelo desemprego. O que vocês acham? \\
$\mathbf{5}^{\mathbf{0}}$ ) Se vocês tivessem um cartão de crédito, usariam ele para quê?
\end{tabular}

Para realização da tarefa investigativa foram necessárias duas aulas chats efetivas. Cada aula teve uma duração média de 2 horas. As duas primeiras questões foram debatidas na primeira aula e as três questões restantes na última aula.

\section{Análise dos dados}

A utilização da ferramenta analítica de categorização das mensagens revelou que, em um aspecto quantitativo, houve intenso fluxo de textos com predominância para mensagens de alunos. Mais de 700 mensagens de texto foram trocadas, das quais $78 \%$ delas foram de estudantes. Um resultado numérico bem similar ao constatado na pesquisa de Silva (2013) realizada em um bate-papo, que indicou $80 \%$ de mensagens de alunos trocadas para resolução de uma atividade matemática.

As aulas chats propiciaram maior participação dos alunos, se comparadas ao que normalmente ocorre nas aulas presenciais tradicionais. Mais do que dados numéricos, a ferramenta analítica evidenciou que houve produção de conhecimento e significado durante as realizações das aulas por meio do ambiente virtual. Das 587 mensagens de texto enviadas por estudantes, 387 ocorrências foram categorizadas como alunos "Respondendo", das quais 77 mensagens foram crenças-afirmações com justificação. Assim, de acordo com o MCS, podemos afirmar que essas 77 ocorrências constituem em produção de conhecimento.

Quanto às análises da construção de conhecimento foram observados episódios nos quais essa construção se manifestou de forma coletiva. Na Terceira Questão, inicialmente os sujeitos de pesquisa diferiram nas respostas quanto ao tipo de operação financeira que cobra taxas de juros menores. Após as respostas divergentes de três alunos, Theefy, uma das integrantes do grupo, expõe 
sua afirmativa com justificação, o que leva os demais estudantes a reavaliarem seus conhecimentos e convergirem para um único pensamento, uma única afirmação, bem como única justificação. Dessa forma constroem coletivamente o conhecimento, conforme se pode analisar no fragmento das mensagens disponibilizado a seguir.

Tabela 3: Fragmento da tabela de Participação dos alunos

\begin{tabular}{|c|c|c|c|l|c|}
\hline 188 & $16: 27$ & Theefy & Todos & $\begin{array}{l}4,94 \% \text { de juros nao é ? ent } \\
\text { acho q o emprestimo pessoal é } \\
\text { o melhor a se fazer }\end{array}$ & ARJ \\
\hline 189 & $16: 28$ & Peter & Todos & É a menor \%? & APC/APP \\
\hline 190 & $16: 28$ & Alisson & Todos & $\begin{array}{l}\text { empréstimo pessoal } \\
\text { por ter a menor taxa de juros }\end{array}$ & ARJ \\
\hline 191 & $16: 28$ & Peter & Todos & $\begin{array}{l}\text { Ataaaaaaaaaaaaa É } \\
\text { a menor } \\
\% \% \% \% \% \%\end{array}$ & ARJ \\
\hline 192 & $16: 29$ & Malia & Todos & $\begin{array}{l}\text { Pq tem a menor taxa de juros }( \\
4,94)\end{array}$ & ARJ \\
\hline 193 & $16: 29$ & Rebeka & Todos & $\begin{array}{l}4,94 \text { pq a taxa de juros vai ser } \\
\text { menor }\end{array}$ & Outro \\
\hline 194 & $16: 29$ & Peter & Todos & $\begin{array}{l}\text { Nossa que burro entendi, tava } \\
\text { eu aqui calculando o negócio } \\
1000 \text { vexedss }\end{array}$ & \\
\hline
\end{tabular}

Fonte: Dados da pesquisa

A produção de significados para termos financeiro-econômicos e matemáticos foram ocorrendo espontaneamente, à medida que as questões da tarefa eram lançadas para os sujeitos de pesquisa. A partir de agora, destacaremos apenas alguns desses episódios, todos ocorridos durante a discussão do item c da Segunda Questão. Esse item em particular busca estimular a produção de significados dos alunos para média de taxa de juros de financiamento cobrada pelos bancos.

No fragmento a seguir observa-se o significado produzido pelo aluno Alisson para média de taxas de financiamento.

Tabela 4: Fragmento da tabela de Participação dos alunos

\begin{tabular}{|l|c|c|c|l|c|}
\hline 370 & $19: 34$ & Prof. & Todos & $\begin{array}{l}\text { c) Qual a média da taxa de } \\
\text { financiamento/parcelamento } \\
\text { de uma fatura? Sr. João } \\
\text { pode pagar o parcelamento } \\
\text { sugerido na fatura? }\end{array}$ & P \\
\hline 371 & $19: 35$ & Alisson & Todos & $\begin{array}{l}\text { geralmente até umas } 24 \\
\text { vezes }\end{array}$ & ARP \\
\hline
\end{tabular}

Fonte: Dados da pesquisa 
Entendemos que para Alisson a média da taxa de financiamento corresponde ao número de parcelas que a fatura pode ser paga.

Na sequência, algumas mensagens adiante, Peter calcula a média da taxa de financiamento usando as taxas de seis bancos distintos. O estudante soma as taxas e divide por seis. Segundo ele, o cálculo não estava correto pelo fato de o valor encontrado ser uma dízima periódica. O significado que esse aluno produz para resposta correta é o de valores exatos ou com poucas casas decimais, levando-o à insegurança quanto ao significado de média aritmética. Vejamos a seguir o fragmento da mensagem de Peter.

Tabela 5: Fragmento da tabela de Participação dos alunos

\begin{tabular}{|l|l|l|l|l|l|}
\hline 390 & $19: 39$ & Peter & Todos & $\begin{array}{l}\text { Eu achei que era pra pegar o } \\
\text { valor de todas as dívidas e } \\
\text { dividir por 6 pq elas são 6, mas } \\
\text { não deu certo, deu uma dizima }\end{array}$ & ARPARJ \\
\hline
\end{tabular}

Fonte: Dados da pesquisa

Ainda no item c dessa questão, Malia faz o cálculo da média da taxa de financiamento da fatura de cartão de crédito que Sr. João pagaria no total de 24 meses, multiplicando a taxa mensal pelo número de meses a serem pagas. Para a aluna, a taxa anual de juros é proporcional à taxa mensal. Vejamos a seguir.

Tabela 6:Fragmento da tabela de Participação dos alunos

\begin{tabular}{|l|l|l|l|l|l|}
\hline 443 & $20: 00$ & Malia & Todos $\begin{array}{l}8,12(\text { ao mes }) \times 24= \\
194,88 \%\end{array}$ & ARP \\
ARJ \\
\hline
\end{tabular}

Fonte: Dados da pesquisa

Esses foram alguns dos fragmentos destacados para visualização da produção de significados dos sujeitos de pesquisa. As interações foram analisadas a partir de leituras plausíveis das mensagens trocadas via chat, considerando as crenças e legitimidades dos estudantes na tomada de decisões mediante situações do planejamento econômico familiar. Assim nosso objetivo foi o de tentar entender o que levou cada sujeito a nos dizer o que disse, conforme proposto por Lins (1999, p. 85).

\section{Considerações finais}


A ferramenta analítica desenvolvida, constituída por 6 categorias e 8 subcategorias, revelou dados quanto ao processo comunicativo de alunos e professores nas aulas chats. Do total de 749 mensagens de texto enviadas durante todas as aulas, mais de $78 \%$ partiram de estudantes, um contraste com a realidade das aulas de matemática de hoje, ditas tradicionais. No entanto, apenas maior participação dos alunos vista de forma isolada não é indicador de que o chat é um ambiente propiciador de produção de significados. Por isso, além de dados quantitativos, a ferramenta explicitou outro ponto. Das 587 mensagens enviadas por alunos, a categoria que obteve maior número de ocorrências foi a de Aluno Respondendo. Dessas, 77 foram crenças-afirmações com justificações, salientando o bate-papo como ambiente favorável para produção de conhecimento e significados pelos estudantes, de acordo com o Modelo dos Campos Semânticos.

A análise das interações registradas no Hangouts, em conjunto com a ferramenta analítica de categorização, também identificou construção coletiva de conhecimento. À medida que um estudante expunha sua crença-afirmação com justificação, outros alunos faziam a leitura e produziam novos conhecimentos, diferente do constituído anteriormente. Foi possível identificar esse tipo de construção em vários momentos durante a pesquisa e um deles se encontra no término da terceira questão proposta na tarefa, quando a aluna Theefy afirma e justifica que a melhor maneira para quitar uma dívida é por meios que implicarão em menores taxas de juros. Após vários debates, outros membros do grupo acabam convencidos e concordando com o posicionamento de Theefy.

Apontamos alguns fatores que podem gerar dificuldades durante aulas chats. Por ser uma ferramenta síncrona, o chat propicia um intenso fluxo de mensagens, o que exige destreza do professor para mediar as interações e disponibilidade de tempo para acompanhar os grupos de alunos durante as aulas. Uma turma grande irá demandar vários grupos e consequentemente muitos horários distintos, já que o recomendado é formação de grupos entre 5 e 7 alunos.

Outro ponto é a conexão com a Internet. O bate-papo exige conexão virtual entre os participantes e pode ocorrer de algum aluno ter a conexão interrompida por instantes, podendo ser minutos, horas ou até mesmo dias. Durante nossa pesquisa tivemos apenas interrupções curtas de conexão que não comprometeram o andamento das aulas.

Para finalizar, nossa investigação revelou eficácia no desenvolvimento de aulas chats de educação financeira com alunos de escola pública. Esperamos que a pesquisa apresentada contribua com profissionais da educação, em especial os professores de matemática que desejam entrelaçar educação financeira e tecnologia. Quanto aos pesquisadores, esperamos que a investigação aqui exposta possa estimular a exploração de ambientes virtuais para se trabalhar esses temas, visando a compreensão da produção de significados de estudantes. A interação e leitura plausível das falas de 
alunos para tarefas de educação financeira com a utilização do vídeo é uma aspiração futura para a ampliação desta pesquisa.

\section{Referências}

BAIRRAL, M. A. Compartilhando e construindo conhecimento matemático: análise do discurso nos chats. BOLEMA, v. 17, n. 22, p. 37-61, 2004.

BAIRRAL, M. A. Discurso, interação e aprendizagem matemática em ambientes virtuais a distância. Rio de Janeiro: Edur, 2007.

BAUMAN, Z. Vida para Consumo: a transformação das pessoas em mercadoria. Rio de Janeiro: Editora Zahar, 2008.

BRASIL/ENEF. Estratégia Nacional de Educação Financeira - Plano Diretor da ENEF. Disponível em http://www.vidaedinheiro.gov.br/wp-content/uploads/2017/08/Plano-DiretorENEF-Estrategia-Nacional-de-Educacao-Financeira.pdf. Acesso em: 21 maio 2018.

GONZÁLEZ, B.; LEÓN, A. Interacción verbal y socialización cognitiva en aula. Acción Pedagógica, $\mathrm{N}^{\circ}$ 18, Enero - Diciembre, 2009, pp. 30 - 41.

HORTON, W. Designing Web-Based Training. New York. Wiley, 2000.

LEONTIEV, A. O Desenvolvimento do psiquismo. São Paulo: Editora Moraes, sd.

LINS, R.C. Por que discutir teoria do conhecimento é relevante para a Educação Matemática. In: Bicudo, M. A. V. (org.). Pesquisa em Educação Matemática: concepções e perspectivas. São Paulo: Editora da UNESP, 1999. p.75- 94.

. O Modelo dos campos semânticos: estabelecimento e notas de teorizações. In: Modelo dos

Campo Semânticos e Educação Matemática: 20 anos de história. Org. Claudia Laus Angelo [et

al.]. São Paulo: Midiograf, 2012.

SAIOL, M. N. O. Chat e Educação Financeira Escolar: investigando interações em um ambiente virtual de aprendizagem. Dissertação (Mestrado em Educação Matemática) Universidade Federal de Juiz de Fora (UFJF), Juiz de Fora, 2017.

SILVA, A. M. Sobre a dinâmica da produção de significados para a matemática. 2003. 163p.

Tese (Doutorado em Educação Matemática) - Universidade Estadual Paulista, Rio Claro.

SILVA, A. M. da; POWELL, A. B. Um programa de educação financeira para a matemática escolar da educação básica. Anais do XI ENEM - XI Encontro Nacional de Educação Matemática, Curitiba, p. 3-19, 2013.

SILVA, A. M. da; POWELL, A. B. Educação financeira na escola: a perspectiva da Organização para Cooperação e desenvolvimento Econômico. Boletim Gepem, nº 66, jan/jun, 2014.

SILVA, L. J. Educação matemática e ambientes virtuais: uma análise das interações ocorridas em um chat educacional. 2013. 299 f. Tese (doutorado) - Universidade Estadual Paulista, Faculdade de Ciências, 2013.

Submetido em março de 2018 Aprovado em maio de 2018 